Maria Auxiliadora Bueno Andrade Megid

Pontifícia Universidade Católica, PUC, Campinas

Email: dmegid@puc-campinas.edu.br

(iD) https://orcid.org/0000-0001-7718-8433

Rosana Catarina Rodrigues de Lima Universidade Campinas, UNICAMP Email: catarinarosana@gmail.com

(D) https://orcid.org/0000-0002-8011-5179

\section{Números e operações aritméticas nas investigações com professores dos anos iniciais}

\author{
Maria Auxiliadora Bueno Andrade Megid \\ Rosana Catarina Rodrigues de Lima
}

\section{Resumo}

Este artigo analisa investigações que tomaram por foco os números e as operações aritméticas em ações voltadas para a formação continuada de professores da Educação Infantil e anos iniciais. Entre as setenta investigações desenvolvidas no período de 2001 a 2012 com professores desses níveis, foi observada a incidência de dezesseis com foco nessa temática. As análises indicam que, embora os números se constituam no principal assunto desenvolvido com as crianças na etapa escolar inicial - apenas quatro com professores da Educação Infantil e doze com os anos iniciais -, os investigadores encontraram poucos avanços relacionados às posturas pedagógicas no trato de tal conteúdo. Foram observadas também as estratégias de repetição de modelos, o que pouco tem contribuído para a compreensão do sistema numérico e sua utilização nos contextos escolares e não escolares. Estratégias envolvendo o cálculo mental e a calculadora ainda têm inserção tímida nas salas de aula. Uma feliz constatação é a de que os trabalhos em colaboração têm apresentado bons resultados, embora ainda não sejam muito empregados.

Palavras-chave: Matemática na infância. Sistema de numeração decimal. Formação continuada de professores.

http://www.perspectiva.ufsc.br http://dx.doi.org/10.5007/2175-795X.2018v36n2p514
Recebido em: 15/09/2017 Aprovado em: 23/10/2017 


\begin{abstract}
Numbers and arithmetic operations with Early Year's teachers' investigations

Keywords:

Mathematics in

childhood.

Decimal

numbering

system. Teachers'

Continued

Training

This article analyzes investigations that took the number and the arithmetical operations in action directed to the continuing teachers' training for Early childhood and initial years education. Among the 70 investigations developed in the period from 2001 to 2012 with teachers of these levels, there were 16 studies with a focus on this theme. The analyses indicate that, although the numbers are the main topic developed with children in the initial school stage - only 4 with pre-school teachers and 12 with the initial years - the researchers found few advances related to pedagogical postures in the treatment of such content. Model repetition strategies are still observed, which have contributed little to the understanding of the numerical system and its use in school and non-school contexts. Strategies involving mental calculation and the calculator still have timid insertion in classrooms. A good finding is that collaborative work has yielded good results, although not widely used yer.
\end{abstract}

Palabras clave: Matemáticas en la Educación infantil y Primaria. Sistema de numeración decimal. Formación continuada de docentes

\section{Resumen \\ Números y operaciones aritméticas en las investigaciones con profesores de Educación Infantil y primeros años de la Educación Primaria}

Este artículo presenta el análisis de investigaciones que tomaron por foco los números y operaciones aritméticas en acciones dirigidas a la formación continuada de profesores de Educación infantil y años iniciales. Entre las 70 investigaciones desarrolladas en el período de 2001 a 2012, con profesores de esos niveles, se observó la incidencia de 16 investigaciones con foco en esta temática. Los análisis indican que, aunque los números se constituían en el principal tema desarrollado con los niños en la etapa escolar inicial - sólo 4 con profesores de Educación Infantil y 12 con los años iniciales - los investigadores encontraron pocos avanzos relacionados a las posturas pedagógicas en el trato de tal contenido. Se siguen las estrategias de repetición de modelos, lo que poco ha contribuido a la comprensión del sistema numérico y su utilización en los contextos escolares y no escolares. Las estrategias que involucran el cálculo mental y la calculadora todavía tienen inserción tímida en las aulas. Una feliz constatación es que los trabajos en colaboración han presentado buenos resultados, aunque todavía no utilizan lo suficiente. 


\section{Introdução}

Neste artigo, objetivamos apresentar uma análise das teses e dissertações defendidas entre os anos de 2001 e 2012, que investigaram as ações relacionadas à formação continuada de professores que atuam na Educação Infantil e nos anos iniciais do Ensino Fundamental (do $1^{\circ}$ ao $5^{\circ}$ ano), em situações que envolvem os números e as operações matemáticas.

Trata-se da análise de um recorte de uma pesquisa maior, do Projeto Universal ${ }^{1}$ intitulado: Mapeamento $^{2}$ e estado da arte da pesquisa brasileira sobre o professor que ensina Matemática. Inicialmente, encontramos setenta trabalhos cujas investigações se desenvolveram a partir da formação continuada de professores da Infância (Educação Infantil e anos iniciais do Ensino Fundamental), entre as quais identificamos dezesseis pesquisas cujo foco de investigação tomava os números e as operações aritméticas por base, nossa perspectiva investigativa.

Utilizamos a análise documental como abordagem metodológica da pesquisa, uma vez que, a partir da identificação dos trabalhos relacionados ao tema do artigo, avaliamos cada uma das investigações, organizando seus dados, analisando-os e interpretando-os de acordo com nossos objetivos (PIMENTEL, 2001). Ou seja, nossos documentos são as teses e as dissertações cuja abordagem se relaciona à formação continuada de professores da infância e cuja temática enfoque os números e as operações aritméticas.

Após apresentar individualmente as dezesseis pesquisas, faremos sua análise a partir de três enfoques por nós indicados como possíveis diferenciais encontrados nas investigações: (i) o cálculo mental, (ii) o foco nas manifestações dos professores sobre o registro escrito e a participação oral das crianças nas aulas de Matemática e (iii) o protagonismo dos professores nos processos formativos. Tais enfoques foram selecionados por considerarmos que, individualmente e em conjunto, podem dar grandes contribuições para o ensino e a aprendizagem no início da escolarização. Buscamos, então, nas pesquisas, analisar se e como os investigadores enfocaram os aspectos relacionados ao cálculo mental, aos registros escritos e ao protagonismo do professor.

\section{A Formação do professor que ensina Matemática nos anos iniciais}

O campo da formação do professor que ensina Matemática (PEM) é uma temática que passou a ser investigada com maior interesse nos vinte últimos anos. Contudo, entre as pesquisas relacionadas à Educação Matemática, ainda são poucas as que se propõem a investigar as práticas de professores da infância. Importante destacar também o número pouco expressivo de teses e dissertações que investigam aspectos do ensino da Matemática em contextos de formação inicial de professores que atuarão na infância (GATTI, 2008). 
Ancorando-nos em Megid (2015), podemos indicar que, nas matrizes curriculares dos cursos de Pedagogia, são encontradas uma ou, na melhor das hipóteses, duas disciplinas dedicadas ao trabalho com a Matemática.

Nesse sentido, cabe destacar a emergência de repensar as matrizes dos cursos de Pedagogia no Brasil, em alinhamento com as afirmações de Serrazina (2012). A autora indica a necessidade de que o conhecimento matemático seja ensinado não de forma isolada, mas interligado com os conhecimentos didático, curricular, dos recursos, sobre os alunos e os contextos. Em seus estudos, a autora enfatiza a relevância da prática supervisionada, de modo que as diferentes etapas de formação possam ser trabalhadas pelos professores numa perspectiva colaborativa e cooperativa.

Como já evidenciado em diferentes pesquisas (CURI, 2005; D’AMBROSIO, 2005; GATTI; BARRETO, 2009; GATTI; BARRETO; ANDRÉ, 2011; MEGID, 2009; MOTA, 2012, entre outras), é pequeno o espaço reservado para a formação dos professores da Educação Infantil e dos anos iniciais do Ensino Fundamental, no que se refere às discussões sobre a Matemática, tanto nos aspectos conceituais quanto metodológicos. Da mesma maneira, não há um consenso quanto à qualificação do formador de professores que será responsável por abordar a Matemática nos cursos de Pedagogia. Seria um matemático? Um pedagogo? Um pesquisador em Matemática, em Educação Matemática ou em Educação?

Da forma como entendemos, esses dois aspectos - a qualificação do professor formador e o tempo destinado à Matemática nos cursos de Pedagogia - revelam qual é a formação que se pretende oferecer aos futuros professores e indicam quais recursos os egressos desses cursos terão para trabalhar com a Matemática na infância.

Entendemos ser necessário refletir sobre como deve ser elaborado um currículo para a formação de professores, norteando-nos por uma questão básica: que profissional se pretende formar? No caso da Pedagogia, há necessidade de formar professores para a infância — Educação Infantil e anos iniciais do Ensino Fundamental - ou especialistas da Educação? Ou, ainda, seria possível formar os dois tipos de profissionais? Gatti e Barreto (2009, p. 41) afirmam que tais modelos de formação devem ser questionados e que os ajustes relacionados às matrizes curriculares feitos pela legislação foram fragmentados, de tal sorte que não proporcionam a integração entre as disciplinas específicas, nem praticam uma formação educacional - geral e didática - que considere o nível de ensino em que o profissional atuará.

Este estudo também defende a necessidade de os professores formados nos cursos de Licenciatura e, de maneira específica, os formados em Pedagogia serem preparados em relação aos fundamentos da educação, ao conhecimento dos conteúdos a serem ministrados e às maneiras diferenciadas de tal abordagem. Tais aspectos resultariam em um processo efetivo de profissionalização docente. 
Em vista disso, a abordagem da Matemática nos cursos de Pedagogia deve estar direcionada para as relações estreitas entre ela, sua história, os conteúdos necessários aos alunos na infância, as possíveis estratégias relacionadas, sem que nos esqueçamos do traço comum encontrado nesses professores em formação: suas dificuldades com a Matemática. Com isso teríamos resguardada uma formação de qualidade para o PEM na infância.

Se ainda há muito a avançar em relação à formação inicial do PEM que atua na Educação Infantil e nos anos iniciais do Ensino Fundamental, a formação continuada desse docente oferece ainda pouco espaço e conta com baixa adesão dos professores. Ancorados em Gatti (2008, p. 57), buscamos identificar como essa formação tem sido compreendida:

[...] ora se restringe o significado da expressão [formação continuada] aos limites de cursos estruturados e formalizados oferecidos após a graduação, ou após ingresso no exercício do magistério, ora ele é tomado de modo amplo e genérico, como compreendendo qualquer tipo de atividade que venha a contribuir para o desempenho profissional - horas de trabalho coletivo na escola, reuniões pedagógicas, trocas cotidianas com os pares, participação na gestão escolar, congressos, seminários, cursos de diversas naturezas e formatos, oferecidos pelas Secretarias de Educação ou outras instituições para pessoal em exercício nos sistemas de ensino, relações profissionais virtuais, processos diversos a distância (vídeo ou teleconferências, cursos via internet etc.), grupos de sensibilização profissional, enfim, tudo que possa oferecer ocasião de informação, reflexão, discussão e trocas que favoreçam o aprimoramento profissional, em qualquer de seus ângulos, em qualquer situação. Uma vastidão de possibilidades dentro do rótulo de educação continuada.

Esse tipo de formação tem sido investigado nas pesquisas que fazem parte do nosso corpus, como indicaremos adiante. Ressaltamos a preocupação com o fato de que essas formações nem sempre estão presentes no cotidiano do professor e, por vezes, pouco (ou nada) influenciam na mudança das práticas pedagógicas de maneira profunda, sobretudo por não encontrarem suporte no interior das escolas.

As mudanças de gestão, tanto das escolas quanto dos programas de políticas públicas, podem levar os professores a não dar continuidade a práticas advindas de alguma formação. As constantes mudanças talvez sejam responsáveis pela pouca reflexão sobre as ações propostas e por essas nem sempre serem adequadas às demandas do contexto em que os professores atuam. Afinal, acreditamos ser possível qualquer mudança, se ancorada na reflexão do professor e decorrente de uma postura investigativa de sua prática; da compreensão de que é possível fazer diferente; de que terá apoio da escola e de sua gestão; e de que seus alunos estão preparados para enfrentar, como parceiros, tais mudanças.

$\mathrm{Na}$ ausência desse processo investigativo, o sentimento de insegurança dificulta ao professor perceber a necessidade de uma abordagem matemática diferente daquela a que se habituou em sua formação básica e faz com que se mantenham, nas salas de aula dos anos iniciais do Ensino Fundamental, aqueles mesmos modelos. 


\section{Delineamento do corpus de análise}

Para selecionar as teses e as dissertações sobre formação continuada do PEM na infância, tomamos como base de dados os trabalhos pertencentes ao corpus do Projeto Universal, em cuja configuração atuamos.

Encontramos 70 trabalhos que abordavam a formação continuada do PEM na/para a infância. Nesse conjunto, foram encontradas 8 dissertações de Mestrado Profissional, 47 dissertações de Mestrado Acadêmico e 15 teses de Doutorado.

Quanto aos objetivos dessas pesquisas, 16 delas tiveram por foco o bloco ${ }^{3}$ Números e Operações; 13 pesquisas, Geometria; os blocos Tratamento da Informação/Estatística e Resolução de Problemas foram abordados nos objetivos de 7 pesquisas, individualmente; e 4 pesquisas investigaram conteúdos relacionados a Números e operações e Geometria. Os demais trabalhos (23) estudaram prioritariamente: Análise de Programas de Formação continuada (5), Trabalho Pedagógico, prática e/ou transformação da prática do professor (6), Concepções sobre a Matemática ou sobre o processo formativo (3), Representações sociais do professor (2), Uso de jogos e materiais (2), Avaliação a partir de distintas perspectivas (2), Formação em Grupo autônomo de professores (1), Saber e aprender de professores tutores (1) e Metodologia de ensino (1).

Do total de trabalhos sobre formação continuada do PEM na Educação Infantil e nos anos iniciais do Ensino Fundamental (70), encontramos apenas 4 cujas investigações foram desenvolvidas na Educação Infantil e outros 4 que abrangiam as duas etapas, tanto a Educação Infantil quanto os anos iniciais do Ensino Fundamental. Os demais trabalhos (63) enfocaram somente os PEM nos anos iniciais do EF.

Neste artigo, ater-nos-emos à análise das dezesseis obras que tomaram por foco investigativo, de modo mais específico, a temática dos Números e operações aritméticas nos processos de formação continuada de professores. Tal interesse se manifestou em razão do número considerável de pesquisas nos últimos doze anos, perfazendo um total de $22,5 \%$ das pesquisas sobre o PEM - formação continuada na infância. Não faremos distinção entre aquelas que focaram o PEM da Educação Infantil, o PEM dos anos iniciais do EF ou o PEM de ambos.

Buscamos identificar nessas pesquisas as propostas relacionadas a partir de três perspectivas: o cálculo mental; o foco nas manifestações dos professores sobre o registro escrito e a participação oral das crianças nas aulas de Matemática; e o protagonismo dos professores nos processos formativos.

\section{Analisando as pesquisas: quais diferenciais apresentam no tratamento dos Números e Operações Aritméticas?}

Entre as dezesseis pesquisas que aqui analisaremos por tomarem como foco o bloco "Números e Operações", nove são dissertações de Mestrado Acadêmico, cinco são teses de Doutorado e duas pesquisas são dissertações de Mestrado Profissional.

A maior incidência neste tema talvez se ancore no fato de que, como afirma Megid (2009, p. 5), “o foco do ensino de matemática nos anos iniciais do Ensino Fundamental concentra-se nas quatro operações aritméticas elementares". A autora destaca ainda que, normalmente, a abordagem dada ao ensino das operações ocorre por meio do algoritmo tradicional; e suas aplicações, em situações denominadas "problemas". 
A grande incidência de trabalhos sobre os Números e as Operações Aritméticas nos instigou a verificar em que essas pesquisas podem contribuir para a formação e o desenvolvimento profissional do PEM na infância, sobretudo em relação aos temas contemporâneos relativos à Educação Matemática.

Apresentamos, inicialmente, uma síntese das dezesseis investigações, agrupando-as segundo a proximidade ou a convergência entre o objetivo investigativo, a questão norteadora da pesquisa ou ainda o foco analítico, para que, ao final do estudo, seja possível analisar as discussões/práticas que tiveram abordagens inovadoras.

Gimenes (2006) investigou as possíveis contribuições de um grupo de professores dos anos iniciais de escola pública, ao estudar os "porquês" do Sistema de Numeração Decimal (SND) e das operações. A autora identificou, por meio de questionário, ser esse conteúdo o de maior dificuldade para ensinar e também o de maior interesse dos professores. Preparou material de apoio para cinco encontros com os professores, recorrendo à História da Matemática, às atividades de investigação e aos materiais manipuláveis. A dinâmica dos encontros envolvia a leitura de textos por ela sugeridos.

Gimenes (2006) privilegiava a apresentação das atividades realizadas durante a formação, com a intenção de que os professores refletissem sobre a prática pedagógica. Nas análises realizadas, sobretudo a partir das anotações do caderno de campo e das transcrições dos áudios, observou que a discussão travada no grupo contribuiu para que percebessem a importância do cálculo mental para a estimativa. Como resultado, destaca que as reflexões sobre a prática e a percepção de lacunas no ensino, observadas nos encontros do grupo de estudo, podem contribuir para que o professor busque mais conhecimentos sobre a Matemática e, inclusive, perceba que a Matemática pode constituir-se em algo a ser construído.

Além de oferecer destaque ao cálculo mental e às estimativas, seu estudo estimulou o trabalho com investigações, o que entendemos ser o diferencial de seu Mestrado.

Sousa (2009) explorou a compreensão, o uso e a coordenação de diferentes registros de representação semiótica por PEM na infância, com foco no SND e nos números e nas operações. Nas vivências pedagógicas trabalhadas com as professoras, a autora identificou as dificuldades relativas a questões conceituais. Constatou que elas não percebiam a relação existente entre o SND e os algoritmos das operações aritméticas e também desconheciam recursos didáticos favoráveis a esse trabalho, mas interessavam-se por eles. Essa pesquisadora enfatiza três fatores que geram dificuldades no trabalho com a Matemática: a não realização de conversões de unidades, em diferentes momentos; a falta de discussão das dificuldades dos professores em formação no curso de Pedagogia; e a centralidade das técnicas algorítmicas nas atividades docentes, em detrimento da resolução de problemas e do trabalho com as frações e decimais, por exemplo.

Entre as seis vivências propostas no processo formativo, uma delas objetivou discutir a importância da comunicação em Matemática, por meio de diferentes representações na resolução de 
problemas: "[...] leitura, interpretação e uso dos diferentes registros, o levantamento de hipóteses, a oralidade, a discussão com o outro para o aprendizado" (SOUSA, 2009, p. 139). Enfatizou a carência de investigações que deem destaque à leitura e à interpretação de textos matemáticos, como os enunciados de problemas ou de questões e histórias envolvendo dados quantitativos, o que auxiliaria o aprimoramento da aquisição da língua materna e a possibilidade de realizar registros de maior complexidade.

Nesta dissertação de Mestrado, entre os três focos por nós escolhidos, identificamos o trabalho relativo ao registro escrito de professores e alunos.

Silva (2011), autor do terceiro trabalho que analisamos, teve por objetivo compreender como os professores ressignificam as operações convencionais de adição e subtração com (re)agrupamento, usando o ábaco manipulativo e informático. O autor aplicou um teste diagnóstico, em que utilizou uma sequência didática com o uso dos ábacos. Dez professores atuantes nos $4^{\circ}$ e $5^{\circ}$ anos do Ensino Fundamental participaram da pesquisa e contribuíram na elaboração do minicurso $O$ ábaco na (re)significação do sistema de numeração decimal e das operações de adição e subtração com (re)agrupamento, desenvolvido em três encontros. E, embora os professores não utilizassem o ábaco tradicional ou digital com frequência em sala de aula, reconheceram a importância da tecnologia informática no trabalho com os alunos.

O estudo constatou que as professoras ampliaram suas estratégias para ensinar as operações com significado, mas constantemente retomavam a forma aprendida quando estudantes das séries iniciais. Ancorado em Lévy (1993), o pesquisador ressalta o diálogo entre os participantes e o formador como um dos aspectos preponderantes na construção do conhecimento, com destaque para três aspectos da comunicação como promotores da aprendizagem: oral, escrito e virtual. De maneira especial, indica que a comunicação durante a sequência didática oportunizou a "interação entre o instrumento de aprendizagem, o registro dos procedimentos ocorridos no instrumento e a abstração matemática nas operações de adição e subtração" (SILVA, 2011, p. 135).

Nesse sentido, entre as perspectivas do nosso trabalho, identificamos, nessa dissertação, o reconhecimento da oralidade presente nos diálogos como fator contributivo para a construção de conhecimentos.

Batista (2012) tomou por dados as ações desenvolvidas em um grupo de estudo formado por professoras de uma escola municipal. Investigou os conhecimentos sobre números e operações manifestados por elas no decorrer dos estudos. Nas conversas e nas respostas a um questionário, identificou suas dificuldades e seus interesses em relação a esse bloco de conteúdo que foi privilegiado, porém sem desconsiderar outras demandas trazidas ao longo do processo, como, por exemplo, as atividades relacionadas aos gráficos.

A dinâmica proposta pela pesquisadora para identificar os conhecimentos dos professores participantes envolveu a produção de atividades, sua aplicação em sala de aula, seu retorno e análise, e a consequente reaplicação das propostas. Sobre o que sabiam a respeito do SND, a autora destacou algumas carências: dificuldades em perceber a decomposição dos números como via facilitadora para o cálculo 
mental; desconhecimento da história do SND e da importância da base dez, entre outras, o que pode trazer obstáculos ao ensino relativo aos campos numéricos e às operações.

O estudo realizado revelou que a discussão de problemas enfrentados em suas práticas diárias favoreceu a troca de experiência entre os professores participantes, propiciou que refletissem e investigassem suas práticas e incentivou-os a tornarem-se protagonistas de seu desenvolvimento profissional.

Santos (2006), por meio de um estudo de caso, investigou a viabilidade de um processo de formação continuada de duas professores dos anos iniciais do EF sobre estruturas multiplicativas a partir de sequências didáticas. Após observar uma aula com cada turma das professoras e analisar as entrevistas realizadas logo após tais observações, organizou um processo formativo, constituído por cinco encontros pedagógicos.

A autora relata que, inicialmente, as professoras propunham atividades individuais, considerando uma única lógica na resolução de problemas. Durante o processo formativo, com a proposta do trabalho em grupo e a argumentação das envolvidas, outros procedimentos passaram a ser valorizados no ensino da Matemática, com uma atenção cuidadosa em relação à quantidade de questões a propor, evitando que se tornassem repetitivas. Embora não tenha sido foco da pesquisa tratar especificamente do cálculo mental, identificamos nas análises das respostas envolvendo cálculo numérico que elas foram classificadas em função da estratégia utilizada na operação: algoritmo e cálculo mental.

Outro aspecto destacado e posto em debate pela pesquisadora refere-se ao direcionamento dado ao diálogo tecido entre a professora e os alunos: a autora observou que os questionamentos da professora eram quase sempre respondidos por ela mesma, o que dava a entender que apresentava apenas um tipo de resolução para determinado problema. Tal fato levou a pesquisadora a cogitar se isso poderia ou não interferir negativamente na compreensão das crianças.

$\mathrm{Na}$ análise desse trabalho, destacamos o estímulo à argumentação dos professores participantes como um aspecto importante no decorrer de um processo formativo, o que pode promover a reflexão, pessoal e em colaboração com os demais envolvidos, sobre as práticas pedagógicas.

Merlini (2012) acompanhou, em três momentos distintos, uma professora da $3^{\mathrm{a}}$ série, participante de um grupo de estudos com dimensões colaborativas: no subgrupo de professoras da $3^{\mathrm{a}}$ série da escola; nas observações das aulas de Matemática da professora; e nas entrevistas realizadas logo após essas aulas. O estudo teve por objetivo "investigar as contribuições e os limites que um processo formativo, com dimensões colaborativas, proporciona no que tange à reflexão na e sobre a prática de uma professora das séries iniciais do Ensino Fundamental, no âmbito do Campo Conceitual Multiplicativo" (MERLINI, 2012, p. 24). 
A autora optou por discutir alguns dos diferentes eixos desse campo conceitual. As ações teóricas envolveram discussões coletivas sobre os testes aplicados aos alunos das professoras de $3^{\text {a }}$ série, refletindo teoricamente variadas situações do campo multiplicativo e elaborando duas situações referentes aos eixos discutidos. E as ações práticas, em um dos momentos, envolveram as situações planejadas, discutindo-as com o grupo. Outro evento consistiu na observação da aula da participante, quando a pesquisadora aplicou as situações de multiplicação elaboradas com o grupo de professoras atuantes na $3^{\text {a }}$ série.

A apresentação e a discussão das análises dos resultados da aplicação das situações planejadas pelos diferentes professores em suas turmas favoreceram o confronto das experiências individuais com as de seus pares e a reflexão sobre suas expectativas iniciais. De maneira específica, a autora analisou a entrevista realizada com a professora pesquisada logo ao final de cada uma das aulas em que essa aplicava as atividades planejadas com seu grupo de $3^{\text {a }}$ série. O estudo relata que o grupo passou por duas etapas: a primeira, numa perspectiva cooperativa; a segunda, em direção a ações mais colaborativas, discutindo os desempenhos e as estratégias utilizadas pelos alunos nas atividades, o que ampliou os conhecimentos relativos ao campo conceitual multiplicativo por parte das professoras. Destaca-se, porém, o tempo restrito como possível limitador do processo formativo com dimensões colaborativas.

Nessa tese, podemos destacar, como aspecto contributivo para (re)significar a prática pedagógica, a interação entre os pares nos diferentes momentos do processo formativo, seja oralmente - nas apresentações/discussões -, seja por escrito, nos planejamentos.

Santos (2012) focou os saberes e conhecimentos do professor polivalente, investigando aspectos do ensinar e aprender Matemática relativos ao campo conceitual multiplicativo no contexto de um grupo com dimensões colaborativas, pautado em estratégias formativas da espiral ação - reflexão planejamento-ação. Seu trabalho aponta indícios de que o grupo tenha vivenciado uma relação colaborativa, na medida em que todos os envolvidos discutiam e decidiam coletivamente estratégias para aplicação da atividade diagnóstica na escola. O pesquisador indica que, no quinto dos dezesseis encontros, as professoras assumiram o protagonismo no processo formativo.

Como resultados, foram identificados avanços na ressignificação e na ampliação das concepções das professoras em relação ao ensino e à aprendizagem, não de forma isolada, mas na interface de quatro dimensões: nas relações professor-estudante; professor pesquisador/formador; no confronto entre a teoria e a prática; e na reflexão sobre a prática pedagógica, sobretudo no processo de reflexão desencadeado pela análise compartilhada das práticas de sala de aula.

Nessa tese, percebemos que a vivência experimentada no grupo com dimensões colaborativas contribuiu para que os professores se percebessem protagonistas de sua aprendizagem docente. 
Justo (2009) investigou o campo aditivo e, em estudo experimental, atuou com professores de duas escolas, uma pública e outra particular, para investigar as influências, no desempenho dos alunos, de um Programa de formação continuada de professores atuantes nas quatro séries dos anos iniciais e de um programa de ensino relativo a problemas aditivos. O estudo em questão contou com duas etapas: aplicação de testes com alunos de turmas experimentais e de controle; e um Programa de Formação continuada desenvolvido com as professoras que atuaram com turmas experimentais.

Este último, composto por quatro oficinas sobre o ensino e a aprendizagem dos problemas aditivos e pelo acompanhamento de planejamentos e observações de aulas durante a implementação do programa de ensino, buscou proporcionar conhecimento sobre os diferentes problemas matemáticos relativos ao campo aditivo. As atividades propostas no programa foram elaboradas e coordenadas pela pesquisadora, que, em busca de repensar a prática como espaço de aprendizagem docente, priorizou questões didáticometodológicas que possibilitassem reflexões sobre uma atuação mais eficaz, provocando o desenvolvimento de competências, em constante diálogo com situações de sala de aula.

Os trabalhos realizados nas oficinas exploraram problemas aditivos; análise da estrutura semântica de situações-problema; aspectos metodológicos na resolução de problemas aditivos; e organização do programa de ensino envolvendo discussões relacionadas aos diferentes aspectos que contribuiriam para a resolução de problemas aditivos em sala de aula. No período de implementação do programa foram realizadas observações de aula e discussões nos encontros de planejamento, organizados pelas professoras em colaboração com a pesquisadora. Os registros das observações de aula permitiram o acompanhamento dos aspectos didático-metodológicos utilizados pelas professoras, que eram posteriormente discutidos pela pesquisadora com cada docente. A autora destaca que, à medida que os professores passaram a conhecer a variedade semântica dos problemas aditivos, aprendiam também a ensinar com maior conhecimento, e, com isso, suas turmas apresentavam melhor desempenho em relação ao tema.

Essa tese revelou que as conversas ocorridas entre pesquisadora e professoras podem fomentar reflexões sobre a prática pedagógica e promover aprendizagens sobre a prática docente.

Motta (2011) investigou a compreensão da Teoria dos Campos Conceituais por professoras envolvidas com a proposta contida no Programa "Orientações Curriculares: Expectativas de Aprendizagem e Orientações Didáticas", decorrente de formações em serviço e/ou cursos promovidos pela Secretaria Municipal de Educação de São Paulo. Ao optar pela história oral como metodologia de estudo, a pesquisadora considera ter permitido às professoras expressarem as transformações ocorridas em seus saberes no âmbito do movimento vivenciado por elas no Programa de reorientação curricular.

$\mathrm{O}$ estudo tomou as entrevistas realizadas com oito professoras como ponto central de suas análises, que foram subdivididas em duas sessões: a primeira relacionada à formação e ao desenvolvimento profissional e a segunda relativa às sondagens realizadas com os seus próprios alunos. 
As entrevistas foram analisadas em quatro grupos, três dos quais se relacionam aos diferentes momentos experienciados pelas professoras durante a implementação do Programa de Orientação Curricular; e um último verificou o modo como as professoras relataram trabalhar com números e operações dentro da perspectiva das Orientações e das análises das sondagens realizadas pelas professoras com seus alunos.

Por meio de algumas entrevistas, a pesquisadora pôde perceber que a aplicação das sondagens provocou as professoras a entender melhor teoricamente os campos conceituais, a partir da participação em cursos de formação promovidos pela Diretoria. Com base tanto nas entrevistas como nas sondagens, constatou-se também que, embora as professoras adotem procedimentos diversificados de cálculo mental, aproximado, com o uso de calculadora -, tais procedimentos são utilizados em função do algoritmo.

Apesar dos desafios, a pesquisadora aponta dois aspectos considerados pelas professoras como importantes para o desenvolvimento profissional: a interação entre os pares na escola e em cursos de formação continuada. As participantes passaram a enfatizar diferentes procedimentos matemáticos, como a decomposição dos números; o trabalho com o cálculo mental; e as justificativas no uso de procedimentos nos algoritmos.

Nessa tese, o que destacamos são as reflexões ocorridas sobre o cálculo mental. Embora as professoras estivessem envolvidas com a proposta de inovação curricular, a pesquisadora pôde identificar que o cálculo mental não vinha sendo percebido como objeto de estudo. Um outro fato também relevante diz respeito às sondagens que as professoras realizaram com os alunos. Os momentos em que aconteciam discussões coletivas a respeito de algumas dessas atividades deram oportunidade para que as professoras expressassem sua compreensão sobre cada uma das situações, o que lhes permitia a identificar as dificuldades encontradas.

Vasconcelos (2008), autora da décima pesquisa analisada, investigou a construção dos conceitos matemáticos sobre divisão, utilizando jogos como recurso metodológico. No decorrer das nove oficinas realizadas num laboratório de ensino de Matemática, dentre outros temas, foram discutidas as ideias de cotição e de repartição, presentes nos problemas de divisão. Após a aplicação de um pré-teste que solicitava a justificativa dos professores quanto às ideias envolvidas nos problemas de divisão, foi proposta uma análise da estrutura dos problemas envolvendo divisão, apresentados nos livros didáticos utilizados pelos professores.

Na sequência, com o objetivo de fazer com que as professoras pudessem estabelecer relações entre os procedimentos e as ideias de divisão, foi aplicado o jogo das sementes, durante o qual foram realizados questionamentos, com o intuito de apresentar uma lógica da divisão: o dividendo é o resultado do produto do divisor pelo quociente mais o resto. Ao considerar o importante papel do trabalho com jogos como recurso para a aprendizagem do professor, a pesquisadora destaca que tal atividade valoriza as 
experiências dos professores e estimula o cálculo mental, as estimativas e a diversidade de estratégias. Ela também ressalta a importância de saber dosar o uso dos jogos e de outros recursos manipulativos, pois o incentivo excessivo pode dificultar o desenvolvimento do cálculo mental por parte das crianças.

O diferencial apresentado nessa dissertação relaciona-se à utilização dos jogos como importante recurso da ação do professor, que, entre outros aspectos, potencializa o desenvolvimento do cálculo mental.

Silva (2007) investigou aspectos que podem influenciar o desenvolvimento profissional de professores do $3^{\circ}$ e do $4^{\circ}$ anos do EF sobre o ensino da representação fracionária do número racional, quando envolvidos em processo formativo na escola em que atuam. Ela inicialmente aplicou um instrumento diagnóstico que lhe permitiu mapear o perfil do grupo de professoras e analisar as estratégias utilizadas por elas e por seus alunos na resolução de problemas envolvendo significados dos números racionais.

Ancorada nos documentos oficiais e em estudos sobre o tema, apresenta algumas considerações relacionadas ao ensino e aprendizagem da representação fracionária dos números racionais e às análises dos resultados do teste diagnóstico. Nas discussões havidas nos encontros, os professores puderam expor suas análises, refletir sobre as situações de ensino relacionadas à construção de conceitos de números racionais e verificar os significados dos números racionais em sua representação fracionária.

Ao tomar por base as reflexões ocorridas nos encontros iniciais, a pesquisadora percebeu não ser possível explorar todos os significados das frações no período proposto, o que a fez selecionar apenas dois: parte-e-todo e quociente, por entender serem eles os que estão mais associados às fases iniciais da construção do conceito de número racional. Propôs atividades que permitiram aos professores vivenciar esses significados da fração, com o uso de materiais como Tangram, Cuisenaire e Dourado. Ela também elaborou e discutiu com o grupo uma sequência de trabalho para o ensino de frações, para possível utilização em sala de aula.

Como resultados, destaca as dificuldades dos professores para entender os significados da representação fracionária dos números racionais. Relata que o melhor desempenho dos professores nas respostas a alguns dos problemas refere-se às questões envolvendo o significado de parte-todo. Outro destaque diz respeito ao espírito colaborativo do grupo como aspecto contributivo para o desenvolvimento dos professores, uma vez que eles se sentiram fortalecidos e inseridos num ambiente que favoreceu os trabalhos de sala de aula. Também afirma que, nos contextos de formação continuada e também inicial de professores, o conceito de números racionais precisa ser complementado com os diferentes significados de sua representação fracionária e comenta os vestígios, identificados nas entrevistas, de descontentamento das professoras com a aprendizagem matemática recebida na sua formação inicial. 
Nessa tese, consideramos que a discussão realizada com o grupo pode ter sido contributiva para a interação ocorrida entre os pares e para a troca de experiências, permitindo o fortalecimento do professor no ambiente formativo e também em sala de aula.

Morais (2010) utilizou a observação participante, os testes e os questionários para investigar as dificuldades e os conhecimentos matemáticos apresentados pelas professoras sobre o tema frações, durante um Curso de Especialização em Educação em Ciências e Matemática para as séries iniciais. O desenvolvimento do trabalho com frações tratado no Curso teve como base o sexto fascículo do PróLetramento - Matemática: Frações e medidas.

Sob orientação do professor formador, as cinco professoras selecionadas se organizaram em grupos e, a partir da observação e da compreensão de um dos materiais didáticos escolhidos, elaboraram uma aula, criando um plano de ação para o ensino de fração. Os dados extraídos da observação direta foram apresentados na forma de episódios. Entre aqueles disponibilizados pelo pesquisador, podemos observar uma maior interação entre as professoras durante as apresentações da aula por elas elaborada. Nessas apresentações, sentiam-se mais encorajadas não apenas a discutir suas produções a partir dos desafios propostos pelas colegas mas até mesmo a expor suas dúvidas relativas ao tema, o que favorecia que explicitassem suas estratégias de resolução dos problemas sobre frações. Demonstraram a necessidade de conhecimentos matemáticos e de maneiras diferenciadas de ensinar-aprender Matemática.

Nesse texto, destacamos o trabalho relativo à oralidade no processo formativo - de modo especial nas apresentações em grupo, que favoreceram que as professoras explicitassem seus conhecimentos sobre frações e reconhecessem a necessidade de aprofundar seus estudos sobre o tema, para poder ensiná-lo para além das regras.

Schastai (2012) investigou os procedimentos metodológicos utilizados por professores no ensino de frações, identificando também os conceitos relativos aos temas dominados pelos professores dos anos iniciais. Detectou inicialmente os conceitos sobre frações dominados pelo grupo de professores por meio de um pré-teste e, após analisá-los, organizou uma sequência de atividades que foram desenvolvidas em sete oficinas pedagógicas, em que atuou como formadora e pesquisadora. Privilegiando o trabalho em grupo, buscou promover interação entre os participantes, problematizando e explorando os conceitos em estudo.

As oficinas abordavam o ensino de frações por meio de diferentes dinâmicas, utilizando 'explosão de ideias' a partir de questão norteadora, de estudo de textos indicados pela pesquisadora e atividades práticas. Os textos eram discutidos em duplas e coletivamente, e os encontros eram avaliados pelos participantes. Uma das propostas, a de utilizar o Tangram para o ensino de frações, surpreendeu as professoras, pois, com uma única atividade, podem ser trabalhados conceitos relativos a diferentes blocos de conteúdo: números e operações, grandezas e medidas, e espaço e forma. 
A pesquisadora aponta a leitura dos textos também como ação inovadora, afirmando que essa era uma prática pouco usada pelas professoras, mas que desde então passou a ser vista como essencial para o entendimento da resolução de problemas. A dinâmica do processo formativo propunha que a organização da oficina tomasse por base a avaliação dos professores da oficina anterior, uma vez que eram consideradas as contribuições e as dúvidas dela advindas. Essa dinâmica parece estimular o protagonismo do professor, na medida em que o envolve em praticamente todas as etapas do processo formativo.

Gautério (2010), autora da décima quarta pesquisa analisada, investigou o processo de (re)significação de conceitos matemáticos numa perspectiva de conhecimento construído por um grupo de professoras que ensinavam uma Matemática que não haviam aprendido de maneira adequada em sua formação básica. Insatisfeitas com o trabalho que realizavam com os alunos dos anos iniciais, as professoras sentiam necessidade de estudar e solicitaram ajuda da universidade.

Em cinco oficinas pedagógicas construídas coletivamente no decorrer do processo formativo, foram abordadas diferentes temáticas relacionadas a conceitos matemáticos, sendo incentivadas a sistematização individual dos conceitos construídos e a socialização com o grupo. A autora destaca que tais ações proporcionam o desenvolvimento de raciocínios e de reflexões diferenciadas.

Nos encontros, as lacunas de aprendizagem de conceitos matemáticos dos participantes iam sendo dissipadas. A pesquisadora preparou atividades que valorizassem os cálculos mental, escrito e aproximado envolvendo operações com números naturais, por meio de estratégias variadas e enfatizando sua compreensão. Constatou que, envolvidas em situações desafiadoras, as participantes aprenderam a construir algoritmos diferenciados, além daqueles a que usualmente recorriam em seus trabalhos. Para ela, o trabalho desenvolvido coletivamente foi essencial para a aprendizagem docente, pois propiciou a discussão e a busca por soluções entre pares, com as quais foi possível às professoras defender suas ideias e criticar os argumentos apresentados pelas colegas.

Nessa dissertação de Mestrado, a sistematização individual e a socialização em grupo podem ser destacadas como momentos que proporcionaram reflexões críticas sobre o ensino de Matemática. Compreendemos que esse processo pode favorecer o protagonismo do professor em seu processo de aprendizagem contínua, com destaque para a importância do trabalho com o cálculo mental em sala de aula.

No décimo quinto estudo, identificamos a única pesquisa que investigou os saberes dos professores da Educação Infantil em relação ao ensino da Matemática, a de Garcia (2006). A autora focou seu estudo na construção do conhecimento numérico, em busca de responder à seguinte questão: “Como as professoras, que participam de um grupo cooperativo, vão construindo novos saberes e novas formas de compreender e lidar com a construção numérica, desenvolvendo uma postura de professora investigadora?" (GARCIA, 2006, p. 19). 
A pesquisadora analisou documentos oficiais sobre o cálculo numérico e destaca que, embora a criança se utilize do apoio dos dedos e de materiais concretos diversos, é "necessário, em algum momento, deixar que as crianças realizem cálculo mental ou estimativas, ou seja, sem o apoio de materiais concretos, pois isto contribui muito na construção do conhecimento numérico" (GARCIA, 2006, p. 53). Enfatiza que o documento não menciona o uso do algoritmo em momento algum. E evidencia o comprometimento do profissional desse nível escolar, pois a ele cabe "propiciar situações nas quais as crianças tenham contato com os números e com a exploração do espaço, pois são essenciais à aprendizagem matemática" (GARCIA, 2006, p. 57).

Com essas inquietações, utilizou-se de uma pesquisa cooperativa envolvendo professores e pesquisador, na qual os professores se assumem responsáveis e protagonistas de sua formação. Entrevistou individualmente seis professoras de uma escola pública, buscando conhecê-las e compreender o que sabiam sobre a construção numérica das crianças. Analisadas as entrevistas, organizou um grupo de estudo, que se reuniu durante treze semanas nos encontros de reunião pedagógica, que contemplaram atividades envolvendo estudos e organização de investigações a serem realizadas com seus alunos. Entre os resultados, a autora considera que a prática investigativa foi fundamental para o grupo, no sentido não só de despertar nos professores um outro olhar em relação à Matemática, ao compreender a necessidade de 'ouvir' as crianças para saber como pensam, mas também de provocar o interesse em estudar e conhecer com maior profundidade conteúdos relacionados à construção numérica.

Nessa dissertação, destacamos a problematização realizada sobre o cálculo mental já na Educação Infantil e o trabalho com as atividades investigativas, que oportunizaram problematizar elementos que podem favorecer o estudo e a compreensão do sistema numérico.

A última pesquisa por nós analisada, a de Fontes (2010), interessou-se por entender e "caracterizar concepções, crenças, valores, atitudes e práticas a respeito do cálculo mental nas séries iniciais do Ensino Fundamental no contexto da rede municipal de São Paulo" (FONTES, 2010, p. 26). Para compreender o trabalho realizado com o cálculo mental ao longo dos últimos anos, a pesquisadora analisou documentos curriculares e de cursos de formação, questionários aplicados a professoras da rede e entrevista com uma educadora/formadora.

A autora buscou significados de 'cálculo mental' sob o ponto de vista de diferentes teóricos. Apoiando-se em Parra (1996), destaca três equívocos atribuídos frequentemente ao uso da expressão 'cálculo mental': a associação do cálculo mental ao cálculo não exato, a confusão estabelecida entre cálculo mental e estimativa, e a associação indevida do cálculo mental ao cálculo rápido. Fontes (2010), ao considerar o universo do $2^{\circ}$ ao $5^{\circ}$ ano do $\mathrm{EF}$, concebe o cálculo mental como aquele que reúne o cálculo oral (mental) ou escrito de operações com números naturais, inteiros e racionais que resultam em valores exatos ou aproximados. 
Apesar das variações identificadas nos documentos analisados quanto à concepção e às metodologias de ensino, a autora destaca a importância do cálculo mental para o desenvolvimento do conhecimento matemático, o que é também recomendado por todos os documentos curriculares propostos pela rede municipal analisados na pesquisa.

Nos relatos das professoras, a pesquisadora constatou que muitas delas consideram o cálculo mental como fundamental para desenvolver o raciocínio matemático, com destaque ao papel ativo da criança em interação com o outro. Entretanto, observou divergências quanto à conceitualização e ao trabalho com o cálculo mental em sala de aula: algumas professoras relacionam o cálculo mental à memorização e à indução do pensamento, o que revela confusões e contradições sobre sua utilização.

A pesquisadora enfatiza outro aspecto relativo à formação do professor dos anos iniciais, comprometida pela falta de estudos específicos de Matemática. Constata que, embora exista o reconhecimento da importância do cálculo mental por parte dos documentos oficiais e dos professores, na prática é um recurso pouco usado em sala de aula. E lembra a necessidade de ampliar a discussão sob duas perspectivas: o papel do cálculo mental na construção dos conhecimentos matemáticos e as metodologias envolvidas no seu desenvolvimento.

Nessa dissertação, dentre os três focos por nós escolhidos, identificamos o trabalho relativo ao cálculo mental como diferencial na investigação relatada.

A seguir, traremos nossas análises a respeito dos três focos que buscamos destacar nas dezesseis investigações anteriormente apresentadas: (i) o cálculo mental, (ii) o foco nas manifestações dos professores sobre o registro escrito e a participação oral das crianças nas aulas de Matemática e (iii) o protagonismo dos professores nos processos formativos.

\section{0 tratamento do Cálculo Mental nas pesquisas}

Com relação à perspectiva do cálculo mental, dentre as dezesseis pesquisas, somente a de Fontes (2010) dedicou-se ao tema como foco de pesquisa. Três outras, as de Motta (2011), Batista (2012) e Vasconcelos (2008), mesmo sem tomá-lo por foco, trouxeram considerações sobre o uso do cálculo mental. Como indicado por Vasconcelos (2008), os jogos podem constituir-se em recurso que também estimula o cálculo mental, embora de maneira não contínua, para não focar o cálculo em processos concretos. Batista (2012) ressalta a pouca habilidade das professoras com os processos de decomposição dos números como auxílio/apoio ao cálculo mental. Por sua vez, Motta (2011) indica que o cálculo mental vem sendo adotado por professoras, porém de maneira mais voltada ao trabalho com os algoritmos convencionais.

A única pesquisa que tomou o cálculo mental como instrumento metodológico a ser enfatizado na aprendizagem matemática nos anos iniciais foi a de Fontes (2010). Ela reconhece a importância do 
cálculo mental nos documentos oficiais, mas avalia que seu uso ainda é insuficiente nas salas de aula. Sugere que se ampliem sua discussão e sua utilização, evitando-se os equívocos relativos à expressão 'cálculo mental'. Outra contribuição de sua investigação é o fato de não considerar o uso da calculadora como oposição ao cálculo mental, uma vez que muitas atividades realizadas com o aparelho possibilitam cálculos eficientes, por privilegiar a construção do percurso para chegar ao resultado.

O que evidenciamos em nossas análises diz respeito à necessidade de pesquisas que investiguem as incompreensões relacionadas ao cálculo mental e ao seu uso, ou ainda o papel da decomposição numérica na compreensão de diferentes algoritmos. Afinal, que conhecimento sobre o cálculo mental necessário ao professor que ensina Matemática na infância tem sido revelado nas pesquisas brasileiras?

Consideramos o cálculo mental como algo importante, que deve ser trabalhado no ensino de Matemática, de maneira especial na infância, mas com a necessária compreensão desse procedimento, desconectando-o do cálculo rápido ou não escrito. Estimular estratégias em cada criança, explorar diferentes procedimentos e socializar os saberes entre os pares são recursos que auxiliam tanto a compreensão do SND quanto das operações aritméticas e podem ajudar no desenvolvimento do raciocínio lógico-matemático. Contribuições dessa natureza são necessárias para o trabalho com as crianças e merecem maiores estudos por parte dos pesquisadores.

\section{A comunicação e a oralidade na formação do PEM reveladas nas pesquisas}

O conjunto de trabalhos analisados no presente estudo permite constatar que temáticas relativas à comunicação nas aulas de Matemática parecem ter sido pouco tratadas no período de 2001 a 2012. Embora não tenhamos localizado pesquisas que tomassem por foco investigativo a comunicação e/ou a oralidade do PEM em processos formativos, identificamos algumas pesquisas cujas análises e discussões nos dão indícios da urgente demanda por estudos sobre o tema.

A pesquisa de Sousa (2009) aponta o envolvimento das professoras participantes em uma vivência com foco na comunicação em aulas de Matemática. Elas demonstraram interesse pelo uso de recursos de comunicação na resolução de situações-problema, ao ler, interpretar e usar diferentes registros em situações que envolveram a discussão de hipóteses com os pares sobre o trabalho desenvolvido. Para que essas ações ocorram, há necessidade de estruturar as aulas de maneira diferente do que normalmente é feito, promovendo leituras e interpretações de textos matemáticos.

Em busca de compreender os 'porquês' de conteúdos matemáticos levantados por professores participantes de um grupo de estudo, Gimenes (2006) revela que as discussões desses conteúdos propiciaram que as professoras percebessem a Matemática como algo a ser construído e acrescenta que 
essa dinâmica permeou o processo formativo, envolvendo leitura de textos e apresentação das atividades dos subgrupos.

Destacamos mais uma vez a importância de, durante as formações de professores, tornar possível a reflexão sobre o aprendido na sua experiência com a Matemática enquanto alunos, comunicando-se com colegas e formadores, buscando compreender e avançar em suas dificuldades para ensinar Matemática.

\section{O protagonismo dos professores nos processos formativos}

Observar o papel assumido pelo professor nos processos formativos apresentados nas teses e dissertações que analisamos, permite-nos dizer que, em alguns casos, há indícios do protagonismo dos professores em seu desenvolvimento profissional, em oposição ao papel de meros cursistas ouvintes. Destacamos o processo formativo proposto por Gimenes (2006), que, a partir das dificuldades e dos interesses dos professores, organiza o material de apoio com sugestões de textos e privilegia a apresentação das atividades realizadas pelos subgrupos, o que permite que os professores reflitam sobre a prática pedagógica e opinem sobre o que e como pretendiam configurar a formação.

De modo semelhante, Batista (2012) realizou um levantamento dos conteúdos de que as professoras sentiam maior necessidade de discutir no processo formativo realizado durante a pesquisa, dando abertura para que outros interesses fossem resguardados nesse percurso, priorizando e encorajando ações que estimulassem o protagonismo do professor naquela formação.

Quanto à assunção do protagonismo do professor, cabe aqui destacar o tempo restrito como possível limitador do processo formativo com dimensões colaborativas, apontado por Merlini (2012). Das duas etapas do processo formativo proposto, somente na segunda o investigador pôde perceber indícios do protagonismo das professoras, quando passaram a tomar algumas decisões em relação às atividades matemática e a discutir sobre as estratégias utilizadas pelos alunos, porém as demais tarefas permaneciam lideradas pelos pesquisadores/formadores.

Enfim, o que esses estudos nos mostram? Que caminhos indicam para as investigações sobre a Matemática no âmbito dos processos formativos do professor que a ensinam na Infância?

As pesquisas parecem reafirmar o que indicamos no início deste artigo: é oferecido pouco espaço à Matemática nos cursos de formação inicial, como deixam ver os resultados apresentados pelas pesquisas trazidas neste estudo. Tal entendimento tem por base o encontrado em algumas dessas pesquisas que, a partir de questionários, identificaram as dificuldades dos professores - e seu interesse por eles - em relação aos diferentes conteúdos que desenvolvem com suas salas de Ensino Fundamental, com destaque para os números e as operações aritméticas. 
Outro aspecto que merece destaque refere-se ao pouco interesse em investigar a formação do professor que ensina Matemática na Educação Infantil: apenas um entre os dezesseis trabalhos se voltou para esse tema, o que pode indicar que a Matemática é pouco explorada nesse nível escolar.

Cabe salientar que, ao mesmo tempo em que os estudos apresentam a ampliação das estratégias das professoras para o ensino das operações, buscando dar significado às ações que realizam, também indicam a frequência com que as participantes mencionam estar impregnada em suas práticas de professoras a forma como aprenderam enquanto estudantes.

Tais fatos parecem indicar a importância de compreender as distintas perspectivas de formação continuada postas ao professor que ensina Matemática na infância. É necessário que a formação ora sugerida responda a essa demanda, esteja presente em cada escola, em cada município, em todo espaço onde a Educação acontece, a fim de atingir todas as crianças da Educação Infantil e dos anos iniciais do Ensino Fundamental.

\section{Balanço síntese das pesquisas analisadas}

Dentre as setenta pesquisas produzidas no período de 2001 a 2012 no contexto de formação continuada do professor que ensina Matemática na infância, discutimos as dezesseis pesquisas que compreendemos privilegiar os conteúdos relacionados aos números e operações aritméticas.

Uma importante constatação desse estudo advém de identificarmos apenas quatro entre as setenta pesquisas inicialmente encontradas relacionadas à formação continuada do PEM na Educação Infantil. Considerando que, a partir da aprovação da Lei de Diretrizes e Bases da Educação Nacional (LDB), há 20 anos, esta etapa escolar passou a faz parte da Educação Básica, entendemos ser este um número pequeno de investigações, pois há muito já se sabe ser possível realizar ações relacionadas à Matemática na primeira infância. Em razão disso, entendemos que investigar a formação continuada do PEM na Educação Infantil trará importantes contribuições para o trabalho do professor da infância.

Percebemos haver ainda carência de estudos que incentivem a compreensão do sistema numérico e da sua utilização nos contextos escolares e não escolares, de maneira específica nas atividades que envolvem as operações aritméticas básicas.

Outra questão a ser destacada a partir do estudo das dezesseis investigações refere-se ao reduzido número de pesquisas interessadas em investigar aspectos relacionados aos números racionais, em sua representação fracionária ou decimal, ou seja, apenas três pesquisas focaram essa temática. Silva (2007) explicita o descontentamento de professores com a aprendizagem do tema em sua formação inicial e destaca a relevância de reflexões sobre a prática, preferencialmente em contexto de trabalho colaborativo, 
para o rompimento de crenças e concepções desses professores em relação ao ensino e à aprendizagem de frações.

Em outra investigação, ao focar nos procedimentos metodológicos no ensino de frações, Schastai (2012) traz como destaque ainda parecer novidade aos professores que trabalhos com uma atividade, no caso, com o uso do Tangram, possibilitem relacionar vários conteúdos (ou blocos de conteúdos). Isso pode indicar a pouca oportunidade de investigação relacionada ao trabalho com a Matemática no interior das escolas.

Embora algumas pesquisas deste estudo estejam apontando para a relevância do cálculo mental em suas análises, percebe-se ser este um recurso pouco explorado na prática pedagógica. Identificamos uma única pesquisa que se interessou pelo tema como foco de investigação, a de Fontes (2010). Sua concepção de cálculo mental como um conjunto de procedimentos de cálculo que podem ser analisados e articulados diferentemente por cada indivíduo para a obtenção mais adequada de resultados exatos ou aproximados, com ou sem o uso de lápis e papel, vai ao encontro da concepção adotada por Matos e Serrazina (1996), que indicam ser o cálculo mental um conjunto de procedimentos caracterizados por serem variáveis, flexíveis, ativos, afirmativos, holísticos e que exigem compreensão, além de oferecer uma aproximação inicial da resposta.

No seu estudo, Fontes (2010) discute os equívocos frequentemente atribuídos à expressão "cálculo mental". Destaca desconsiderar a oposição entre a calculadora e a ideia de cálculo mental e argumenta, ancorando-se em Albergaria e Ponte (2008), a favor da potencialidade do uso da calculadora em sala de aula, para explorar de modo mais aprofundado os conhecimentos numéricos. Suas análises constataram a relevância dada ao tema pelos documentos oficiais e também pelos professores. Entretanto, enfatiza que, na prática, esse recurso é pouco utilizado, e a discussão a seu respeito merece ser ampliada, considerando o papel do cálculo mental na construção de conhecimentos matemáticos e as metodologias envolvidas no seu desenvolvimento.

Outro aspecto que ressaltamos, após analisar as dezesseis pesquisas, relaciona-se à pouca utilização das investigações matemáticas nas pesquisas referentes ao período estudado e ao tópico Números e operações aritméticas na infância. Apenas Garcia (2006) organizou investigações para desenvolvê-las com o grupo de professoras da Educação Infantil e registrou o potencial desse trabalho na formação continuada. Utilizar as investigações em momentos de formação privilegia que aflore a reflexão relacionada ao que já se sabe e ao que se pretende ensinar. E ainda pode incentivar os professores a utilizarem práticas semelhantes com seus alunos.

Como última consideração, trazemos nossa preocupação com a necessidade de aprofundar o conceito e as práticas de grupos colaborativos. Na presente pesquisa, constatamos que os professores que trabalham em colaboração têm manifestado avanços em suas ações docentes, compreendendo melhor o 
que ensinam, planejando com mais recursos e profundidade suas aulas, atingindo maior satisfação com a aprendizagem de seus alunos.

Enfim, a pesquisa relacionada à formação do PEM na infância ainda merece muita atenção. Novos estudos, sob diferentes perspectivas, precisam ser realizados e divulgados, sempre com a intenção de que a Matemática seja aprendida com significado por todos, como recurso para a constituição de cidadãos que possam compreender o mundo e nele atuar com eficácia e liberdade.

Notas

${ }^{1}$ Projeto financiado pelo CNPq e coordenado pelo Grupo de Estudos e Pesquisas sobre Formação de Professores de Matemática (GEPFPM), coordenação geral do professor doutor Dario Fiorentini (FE/Unicamp).

${ }^{2}$ O mapeamento resultante desse projeto encontra-se disponível em Fiorentini, Passos e Lima, (2016): $<$ https://www.fe.unicamp.br/pf-fe/pf/subportais/biblioteca/fev-2017/e-book-mapeamento-pesquisa-pem.pdf>. 


\section{REFERÊNCIAS}

ALBERGARIA, I. S.; PONTE, J. P. Cálculo mental e calculadora. In: CANAVARRO, A. P.; MOREIRA, D.; ROCHA, M. I. (Ed.). Tecnologias e educação matemática. Lisboa: SEM-SPCE, 2008. p. 98-109.

BATISTA, C. M. S. Percepções e conhecimentos de professoras que ensinam Matemática nos anos iniciais do Ensino Fundamental acerca do ensino de números e operações. 2012. 148 f. Dissertação (Mestrado em Educação Matemática) - Universidade Federal do Mato Grosso do Sul, Campo Grande, 2012.

CURI, E. A matemática e os professores dos anos iniciais. São Paulo: Musa, 2005.

D’AMBROSIO, B. S. Conteúdo e metodologia na formação de professores. In: FIORENTINI, D.; NACARATO, A. M. Cultura, formação e desenvolvimento profissional de professores que ensinam matemática. Campinas-SP: Musa, 2005.

FIORENTINI, D. et al. O professor que ensina matemática como campo de estudo: concepção do projeto de pesquisa. In: FIORENTINI, D.; PASSOS, C. L. B.; LIMA, R. C. R. Mapeamento da pesquisa acadêmica brasileira sobre o professor que ensina matemática. Campinas: Unicamp,( 2016). p. 17-43.

FIORENTINI, D.; LORENZATO, S. Investigação em Educação Matemática: percursos teóricos e metodológicos. Campinas: Autores Associados, 2006. 226p.

FONTES, C. G. O valor e o papel do cálculo mental nas séries iniciais. 2010. 220 f. Dissertação (Mestrado em Educação) - Universidade de São Paulo, São Paulo, 2010.

GARCIA, M. F. Os saberes dos professores de educação infantil em relação à construção numérica: formação de professores em um grupo cooperativo. 2006. 251 f. Dissertação (Mestrado em Educação Matemática) - Pontifícia Universidade Católica de São Paulo, São Paulo, 2006.

GATTI, B. A. Análise das políticas públicas para formação continuada no Brasil, na última década. Revista Brasileira de Educação, [S.1], v. 13, n. 37, p. 57-70, jan./abr. 2008.

GATTI, B. A.; BARRETO, E. S. S. Professores do Brasil: impasses e desafios. Brasília: Unesco, 2009.

GATTI, B. A.; BARRETO, E. S. S.; ANDRÉ, M. E. D. A. Políticas docentes no Brasil: um estado da arte. Brasília: Unesco, 2011.

GAUTÉRIO, V. L. B. (Re)significando aprendizagens matemáticas: uma experiência vivida com professoras dos anos iniciais. 2010. 102 f. Dissertação (Mestrado em Educação em Ciências) - Universidade Federal do Rio Grande-FURG, , Rio Grande, 2010.

GIMENES, J. Contribuições de um grupo de estudo para a formação matemática de professoras que lecionam nas séries iniciais. 2006. 124 f. Dissertação (Mestrado em Educação Matemática)) - Universidade Estadual Paulista, Campus Rio Claro, Rio Claro, 2006.

JUSTO, J. C. R. Resolução de problemas matemáticos aditivos: possibilidades da ação docente. 2009. 197 f. Tese (Doutorado em Educação) - Universidade Federal do Rio Grande do Sul-UFRGS, Porto Alegre, 2009.

LÉVY, P. As tecnologias da inteligência: o futuro do pensamento na era da informática. 2. ed. Rio de Janeiro: Editora 34, 1993.

MATOS, J. M.; SERRAZINA, M. L. Didática da Matemática. Lisboa: Universidade Aberta, 1996. Cap. 7. "Recursos na aula de Matemática".

MEGID, M. A. B. A. Formação inicial de professoras mediada pela escrita e pela análise de narrativas sobre operações numéricas. 2009. 219f p. Tese (Doutorado em Educação Matemática), - Universidade Estadual de Campinas, Campinas,. 2009. 
MEGID, M. A. B. A. Insubordinação criativa consentida é esperada na formação de professores dos anos iniciais. In: D'AMBROSIO, B. S.; e LOPES, C. E. (Orgs.) Ousadia Criativa nas Práticas de Educadores Matemáticos. Campinas, S. P.. Mercado de letras, 2015. p. 21-41.

MERLINI, V. L. As potencialidades de um processo formativo para a reflexão na e sobre a prática de uma professora das séries iniciais: um estudo de caso. 2012. 262 f. Tese (Doutorado em Educação Matemática) Pontifícia Universidade Católica de São Paulo, São Paulo, 2012.

MORAIS, E. C. Ensinar-aprender frações em um curso de formação continuada para professores dos anos iniciais do Ensino Fundamental: conhecimentos e dificuldades evidenciadas. 2010. 121 f. Dissertação (Mestrado em Educação em Ciências e Matemática) - Universidade Federal do Pará, Belém, 2010.

MOTA, A. P. A. Operações aritméticas: dificuldades indicadas pelas futuras professoras do ensino fundamental. 2012. 80f. Dissertação (Mestrado em Educação) - Programa de Pós-Graduação em Educação, Pontifícia Universidade Católica de Campinas, Campinas, 2012.

MOTTA, C. D. V. B. Um retrato de aprendizagem em Educação Matemática: professoras dos anos iniciais do Ensino Fundamental em processo de inovação curricular. 2011. 346 f. Tese (Doutorado em Educação) Universidade de São Paulo, São Paulo, 2011.

PARRA, C. Cálculo mental na escola primária. In: PARRA, C.; SAIZ, I. (Orgs). Didática da Matemática: reflexões psicopedagógicas. Porto Alegre: Artes Médicas, 1996. p. 186-235.

PIMENTEL, A. O método da análise documental: seu uso numa pesquisa historiográfica. Cad. Pesquisa, São Paulo, n. 114, p. 179-195, nov. 2001.

SANTOS, A. Processos de formação colaborativa com foco no Campo Conceitual Multiplicativo: um caminho possível com professoras polivalentes. 2012. 340 f. Tese (Doutorado em Educação Matemática) - Pontifícia Universidade Católica de São Paulo, São Paulo, 2012.

SANTOS, R. R. Formação continuada de professores sobre estruturas multiplicativas a partir de sequências didáticas. 2006. 220 f. Dissertação (Mestrado em Educação) - Universidade Federal de Pernambuco, Recife, 2006. SCHASTAI, M. B. Pró-letramento em Matemática: problematizando a construção do conceito de frações - uma contribuição para a formação de professores. 2012. 204 f. Dissertação (Mestrado em Ensino de Ciência e Tecnologia Profissional) - Universidade Tecnológica Federal do Paraná-UTFPR, Ponta Grossa, 2012.

SERRAZINA, M. L. M. Conhecimento matemático para ensinar: papel da planificação e da reflexão na formação de professores. Revista Eletrônica de Educação. São Carlos, v. 6, n. 1, p. 266-283, 2012.

SILVA, A. F. G. O desafio do desenvolvimento profissional docente: análise da formação continuada de um grupo de professoras das séries iniciais do Ensino Fundamental, tendo como objeto de discussão o processo de ensino e aprendizagem das frações. 2007. 308 f. Tese (Doutorado em Educação Matemática) - Pontifícia Universidade Católica de São Paulo, São Paulo, 2007.

SILVA, J. B. R. Formação continuada de professores que ensinam Matemática: o papel do ábaco na ressignificação da prática pedagógica. 2011. 179 f. Dissertação (Mestrado em Ciências Naturais e MatemáticaProfissional) - Universidade Federal do Rio Grande do Norte, Natal, 2011.

SOUSA, A. C. G. Representações semióticas e formação docente para o trabalho com números e operações nos anos iniciais do Ensino Fundamental. 2009. 157 f. Dissertação (Mestrado em Educação) - Universidade Estadual do Ceará, Fortaleza, 2009.

VASCONCELOS, C. F. B. S. A (re)construção do conceito de dividir na formação dos professores: o uso do jogo como recurso metodológico. 2008. 159 f. Dissertação (Mestrado em Educação Brasileira) - Universidade Federal de Alagoas, Maceió, 2008. 